\title{
Hull Leads Executive Committee in 1997
}

Robert Hull, associate professor in the Materials Science and Engineering Department at the University of Virginia, automatically assumes the position of the 1997 Materials Research Society president from his position as First Vice President in 1996. He succeeds Carl V. Thompson from the Massachusetts Institute of Technology who now serves MRS as immediate past president.

Robert J. Nemanich (North Carolina State University) moves from his elected position in 1996 of Second Vice President to Vice President (President-Elect). Beginning in 1997, MRS no longer has a Second Vice President, and for 1998, members will elect a Vice President (President-Elect). Alan J. Hurd (Sandia National Laboratories) is the newly elected Treasurer for a two-year term, and Kevin Jones (University of Florida) enters the second year of his two-year term as Secretary. MRS Council has re-elected two councillors to serve one-year terms on the executive committee: Ronald Gibala and Alan I. Taub.

The newly elected MRS councillors for 1997 are Theodore M. Besmann, Oak Ridge National Laboratory; Amy J. Moll, Hewlett Packard; and Timothy D. Sands, University of California-Berkeley. They join the following current members of council: Cammy R. Abernathy, University of Florida; Harry A. Atwater, California Institute of Technology; Charles B. Duke, Xerox Wilson Center; Ronald Gibala, University of Michigan; Martin L. Green, Lucent Technologies/Bell Labs; James M.E. Harper, IBM T.J. Watson Research Center; Gabrielle G. Long, National Institute of Standards and Technology; Virginia M. Oversby, Lawrence Livermore National Laboratory; Manfred Rühle, Max-PlanckInstitut für Metallforschung; Lyle $\mathbf{H}$. Schwartz, National Institute of Standards and Technology; Alan I. Taub, Ford Motor Company; and James S. Williams, Australian National University.

\section{Robert Hull}

\section{President}

Robert Hull is an associate professor in the Materials Science and Engineering Department at the University of Virginia. His research interests in the past decade have included superionic conductors, radiation damage mechanisms, metallic superlattices, tribology, ceramic superconductors, ion implantation, x-ray mirror materials and quantum wires and dots. The primary focus of his research,

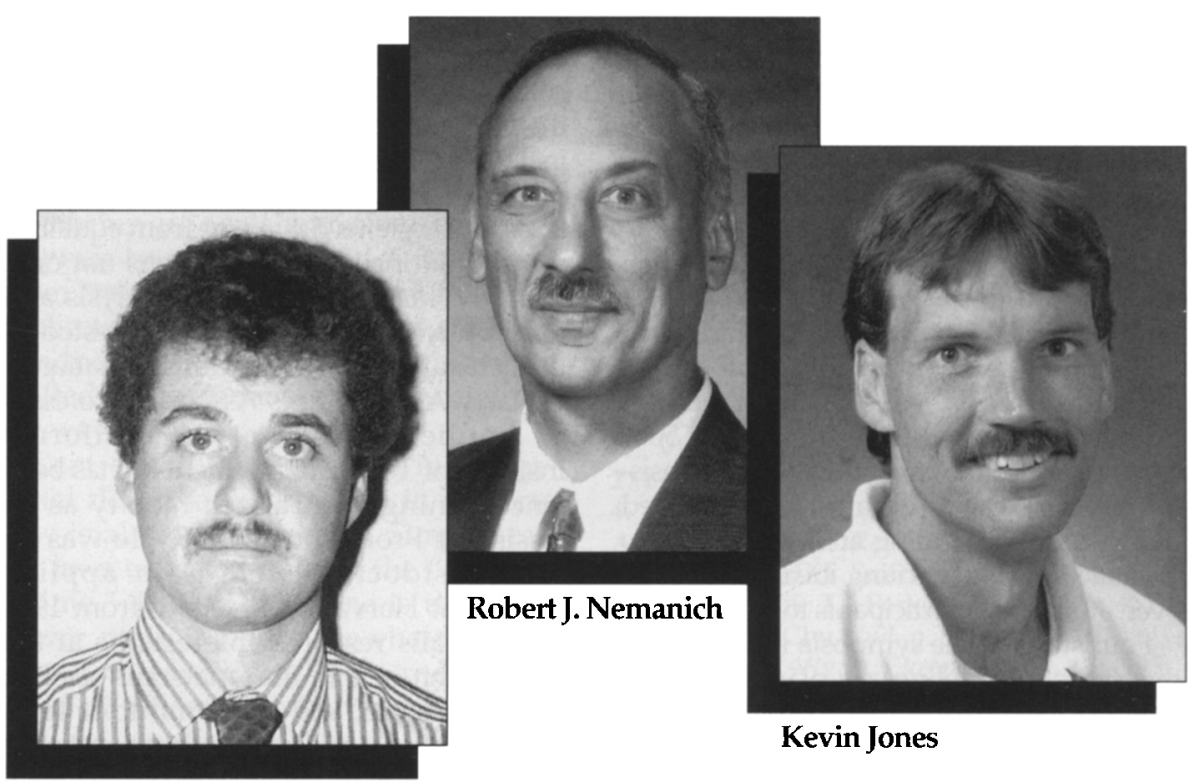

Robert Hull

however, is in electronic materials, particularly the structure and properties of interfaces, defects, and thin films. The principal experimental tools used in his research are electron microscopy and focused ion beams.

Prior to joining the University of Virginia, Hull worked in the Materials Research Department at AT\&T Bell Laboratories and the Materials Characterization Department at Hewlett Packard Laboratories. Hull received his $P h D$ degree in materials science from Oxford, England, in 1983.

Along with serving MRS as first vice president, Hull served as second vice president (1995), on Council from 1992 to 1994, and on the Publications, Program, Academic Affairs, and Continuing Education Committees. He co-chaired three MRS symposia and was a chair for the 1990 MRS Fall Meeting.

\section{Robert J. Nemanich}

Vice President

(President-Elect)

Robert J. Nemanich, professor of physics and an associate member of the Department of Materials Science and Engineering at North Carolina State University, coordinates an interdisciplinary research program involving postdoctoral research associates and undergraduate and graduate students from the departments of materials science, physics, and electrical engineering. With his main research interest area in electronic materials, Nemanich's current research topics include diamond and other wide-bandgap semiconductor surfaces and interfaces, heteroepitaxy on $\mathrm{Si}$, semiconductor surface cleaning and preparation, and amorphous and microcrystalline semiconductors.

After receiving his BS degree in physics from Northern Illinois University in 1969 and his PhD degree in physics from the University of Chicago in 1976, Nemanich worked at Xerox Palo Alto Research Center from 1976 to 1986 . He was involved with research, development, and research management in the Integrated Circuit and General Science Laboratories.

Within MRS, Nemanich served as second vice president (1996), and, prior to that, as chair of the Continuing Education Committee for three years. He has served on the Publications and Program Committees, co-organized five MRS symposia, and co-chaired the 1989 MRS Fall Meeting.

\section{Kevin Jones}

Secretary

Kevin Jones is an associate professor of materials science and engineering at the University of Florida where he directs graduate students investigating microstructural defects which arise from either the growth (metalorganic chamical vapor deposition and metalorganic molecular beam epitaxy) or processing (ion implantation and annealing) of $\mathrm{Si}, \mathrm{GaAs}, \mathrm{GaP}$, $\mathrm{ZnSe}$, or GaN. With his research interest in the area of processing and characterization of semiconductors, Jones cofound- 


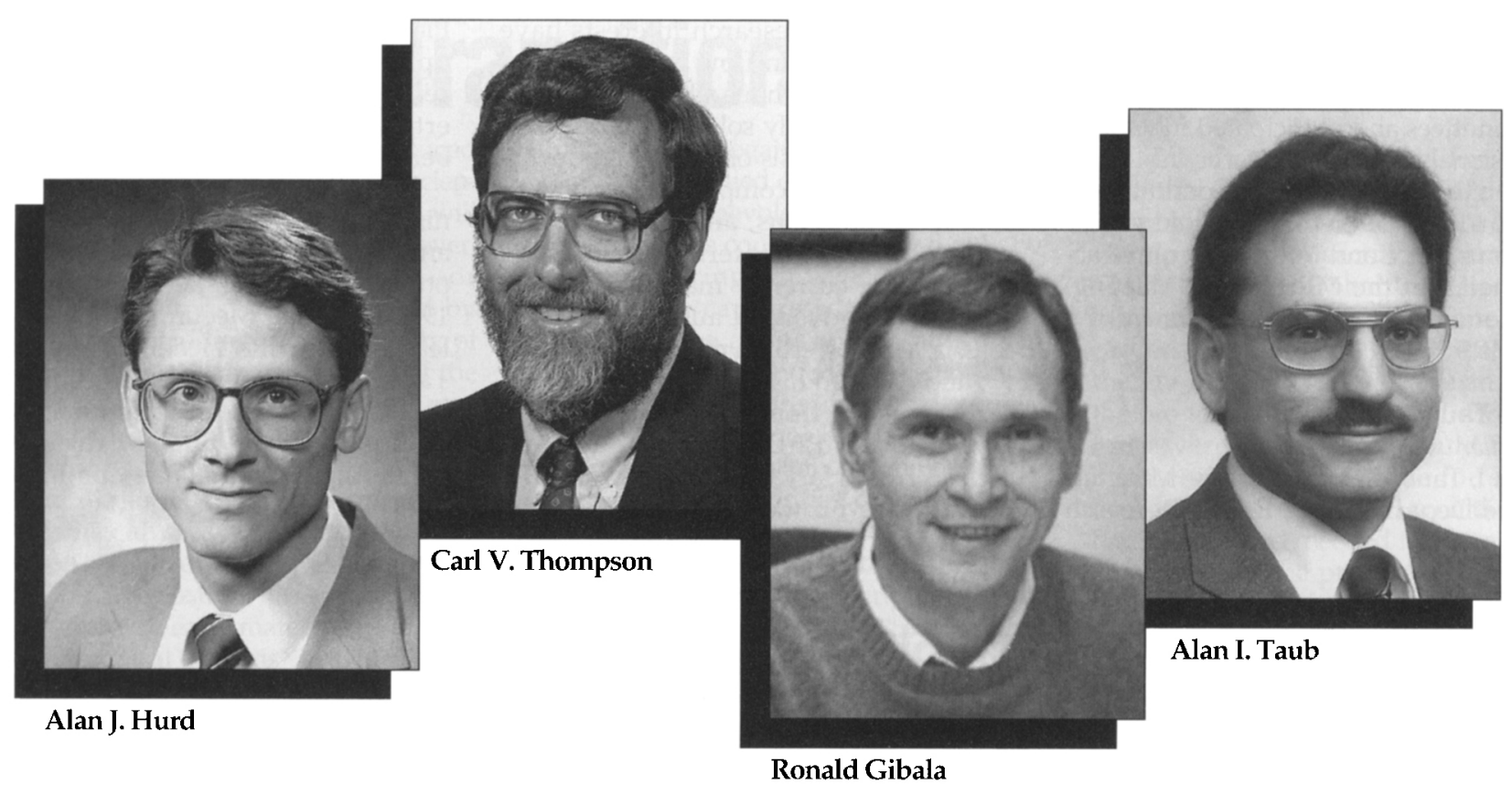

ed the FIRST Center (Florida Integrated Research in Silicon Technologies) to assist the silicon integrated circuit industry to better understand and model the effect of processing-induced defects on device properties.

Jones received his MS (1985) and $\mathrm{PhD}$ (1987) degrees in materials science and engineering from the University of California-Berkeley. He served as a consultant or several semiconductor processing firms including TRW Inc., Motorola, National Semiconductors, IBIS Technologies, and Kopin Corporation.

Within MRS, Jones is continuing his second year as Secretary. He served on MRS Council and on the MRS Membership Committee, chaired the MRS Academic Affairs Committee, and co-organized MRS symposia.

\section{Alan J. Hurd}

Treasurer

Alan J. Hurd is manager of the Theoretical and Computational Materials Department at Sandia National Laboratories and adjunct professor of physics at the University of New Mexico. His research interests center around complex fluids, including colloidal physics, sol-gel film technology, and the physics of dipcoating. His other research interests include fractals, two-dimensional phases, aerosols, imaging ellipsometry, granular materials, and small-angle scattering.

Prior to joining Sandia in 1984, Hurd taught physics at Brandeis University. He has served on advisory groups for Los Alamos National Laboratory, the
National Research Council, the National Renewable Energy Laboratory, and the University of New Mexico. He has been awarded three research awards by the Department of Energy. Hurd's BS degree from Colorado School of Mines and his $1981 \mathrm{PhD}$ degree from the University of Colorado are in physics.

Hurd is leaving his position as councillor for the position of Treasurer. His contributions to MRS include participation on the Long-Range Planning Committee, the Academic Affairs Committee, the Membership Committee, and MRS Bulletin Subcommittee; symposia organizer; short course instructor; and chair of the 1994 Spring Meeting.

\section{Carl V. Thompson}

Immediate Past President

Carl V. Thompson has been a professor of electronic materials in the Department of Materials Science and Engineering at the Massachusetts Institute of Technology (MIT) since 1983. His research interests focus on relationships among processing, structure, properties, and performance of thin films used in electronic devices and circuits and magnetic devices and systems. He and his students have studied modeling of grain growth and recrystallization in semiconductor and metallic films, new thin-film processing techniques, and the effects of microstructure on electromigration in interconnects, contacts, and vias.

Thompson received his MS and PhD degrees in applied physics from Harvard University. During the 1990-1991 academic year, he was a U.K. Science and Engineering Research Council visiting fellow at Cambridge University. He has worked briefly for General Electric and U.S. Steel and has consulted for such firms as IBM and Digital Equipment Corporation.

Among his numerous contributions to the Society are serving as president; second and first vice presidents; symposia organizer; 1990 MRS Spring Meeting co-chair; and serving on the Continuing Education, Program, and Academic Affairs Committees. Thompson chaired the Audit Committee for two years, and completed a three-year term on Council in 1993.

\section{Ronald Gibala \\ Councillor}

Ronald Gibala is a professor in and former chair of the Department of Materials Science and Engineering at the University of Michigan. He directs the Center for High Temperature Structural Metallic Materials, an interdisciplinary program funded by the Air Force Office of Scientific Research. His current research interests are in the area of mechanical behavior of materials, particularly intermetallic alloys and related quasi-brittle materials.

After receiving his BS degree in metallurgical engineering from Carnegie Mellon University (1960) and his MS (1962) and PhD (1964) degrees in metallurgical engineering from the University of Illinois at Urbana-Champaign, Gibala taught at Case Western Reserve University from 1964 to 1984 and was associate director and director of the CWRU Materials Research Laboratory during the 
latter part of that time. He joined the University of Michigan in 1984.

Gibala has served on numerous advisory committees and participated in various professional societies. He served as councillor on the MRS Executive Committee in 1996. In 1988, he co-organized a symposium on science and technology of refractory metals at the MRS Spring Meeting. $\mathrm{He}$ is one of the meeting chairs for the 1998 MRS Spring Meeting.

\section{Alan I. Taub \\ Councillor}

Alan I. Taub is manager of the Materials Science Department at Ford's Research
Laboratory. His research interests have included studies in flow and structural relaxation in amorphous alloys, mechanical properties of rapidly solidified nickel-base alloys with emphasis on improved ductility in intermetallic compounds for aircraft engine applications, and processing of superconducting materials for medical magnets. He currently manages research activities on advanced automobile body, chassis, and powertrain materials.

Taub received his $\mathrm{ScB}$ degree in materials engineering from Brown University in 1976 and his PhD degree in applied physics from Harvard University in 1979. From there he worked with General
Electric's Corporate Research and Development Center until 1993. He most recently managed the Materials Properties and Processes Laboratory at GE before joining Ford.

Since joining MRS, Taub has co-organized two symposia on amorphous alloys and high-temperature materials and two on manufacturing, he has co-chaired the 1993 MRS Fall Meeting, and is currently leading the MRS Headquarters Building Task Force. Taub served as councillor on the MRS Executive Committee in 1996. $\mathrm{He}$ is also a member of the External Affairs and Public Affairs Committees.

MIRIS

\section{Journal of Materials Research: Status Report 1996}

The Journal of Materials Research (JMR) continues as a primary archival, cross-disciplinary journal in materials science and technology. It remains in the top $5 \%$ of all journals in materials in terms of high citations/paper and low subscription cost/ page. It is supported by an unusually dedicated group of editors.

The increasingly faster pace in materials has led to an increased need for rapid publication. JMR communications are now handled by two special editors, Patrick Gallagher and Robert Frankenthal. We particularly invite submission of new, highquality work for consideration as communications.

By its nature, materials constantly moves in new directions. In an effort to present perspectives on emerging areas and updates on continuing, exciting areas, we have from time to time published "Focus Issues" in which a substantial part of one JMR issue is devoted to papers on a common theme, gathered together by a focus issue editor. Two past issues were on "Green Materials," edited by Julian Szekely, and "Synthesis and Processing," edited by Peter Esherick. Future focus issues will include "Green Materials II," "Superconductivity-Ten Years of Progress," and "Photovoltaics." Paul Siffert has recently agreed to act as Focus Issue Editor.

Under the guidance of two review editors, Lynn Boatner and Harry Leamy, IMR continues to commission review articles on appropriate topics. Our goal has been at least six high quality reviews per year and we are approaching that level. Review editors invite suggestions for reviews.

Finally, JMR is entering the electronic age. At the 1996 MRS Fall meeting the first CD product for Journal of Materials Research was demonstrated. JMR Volume 11 (January-December 1996) plus the entire $J M R$ cumulative indexes (11 years) have been put onto a CD-ROM. The software used is Adobe Acrobat Reader ${ }^{\text {TM }}$ which is operational on Macintosh, Windows, and Unix formats. The cumulative indexes include full abstracts. All articles in Volume 11 as well as the indexes are searchable by title, author, material, key word, subject, date of publication, or word stemming.

ROBERT A. LAUDISE JMR Editor-in-Chief

\section{ND INDUSTRIAL ENERGY EFFICIENCY SYMPOSIUM \& EXPO}

\section{FEBRUARY 25-27, 1997 Hyatt Regency Crystal City • Alexandria, Virginia}

Sponsored by the U.S. Department of Energy and the Office of Industrial Technologies

This two-day conference will spotlight the public-private research and development partnerships that are in place in seven key process industries: aluminum, chemicals, forest products, glass, metal casting, petroleum, refining, and steel.

Find out how these industries will be gaining a competitive edge in rapidly changing global markets. See how the industries of the future will meet the energy, environmental, and economic challenges of tomorrow. Learn how collaborative R\&D addresses industry needs and accelerates the development of crosscutting technologies such as advanced turbines, textiles, advanced materials and composites, forging, heat treating and welding.

For more information, contact Conference Services, Energetics, Inc., 7164 Gateway Drive, Columbia, MD 21043; fax 301-621-3329; e-mail OIT.EXPO97@HQ.DOE.GOV.
International Conference on Advanced Materials (ICAM'97) and European Materials Research Society (E-MRS'97)

Strasbourg, France June 16-20, 1997

Deadline for Abstract Submission: February 1, 1997

For more information, contact P. Siffert, Conference Secretariat, E-MRS 1997 Spring Meeting, BP 20, 67037 Strasbourg Cedex 2, France; phone 33-03-88-10-65-43; fax 33-03-88-10-62-93; e-mail EMRS@FRCPN11.IN2P3.FR. 